\title{
Couple Pregnancy Intentions and Induced Abortions in the United States
}

\author{
Susan Cha ${ }^{1 *}$, Derek A. Chapman ${ }^{1}$, Wen Wan ${ }^{2}$, Candace W. Burton ${ }^{3}$, Steven H. Woolf ${ }^{1}$, Saba W. Masho ${ }^{1}$
}

\begin{abstract}
Objectives: Approximately half of US pregnancies are unintended and $43 \%$ of these end in induced abortions. Male partners and their involvement in reproductive decisions is not well understood. We examined the association between couple pregnancy intentions and induced abortion in US women.

Materials and Methods: Data came from the National Survey of Family Growth (2006-2010). Primiparous women who lived with one husband or partner before conception of their first pregnancy were included in the analysis $(\mathrm{N}=4263)$. Multiple logistic regression was used to assess the relationship between couple pregnancy intentions and induced abortion of first pregnancy.

Results: Approximately $17.1 \%$ of women reported discordant intentions and $32.3 \%$ reported that pregnancy was unintended by both parents. Among these couples, the women were more likely to be unmarried, minorities, of lower income and education, and 19 years of age or younger at conception than were couples in which both parents intended pregnancy. Compared to couples with a mutually intended pregnancy, those with discordant pregnancy intentions were significantly more likely to have induced abortion, even in women who desired pregnancy.

Conclusion: Partners had a vital role in decisions to have an induced abortion. Health providers should consider the interpersonal decision-making process in couples to best prevent induced abortions due to unintended pregnancy. Providers should also be aware of the role of violence on reproductive decisions in couples with discordant pregnancy intentions. Women in healthy relationships can benefit from having frequent conversations about pregnancy with their partners.

Keywords: Abortion, Contraception, Unwanted pregnancy, Family planning services, Intimate partner violence
\end{abstract}

\section{Introduction}

In the United States, approximately half of all pregnancies are unintended and $43 \%$ of these terminate in induced abortions (1). Induced abortions related to unintended pregnancies account for $20 \%$ of all pregnancies (2) with markedly increased rates among low-income, minority populations $(2,3)$. Other groups-e.g., women who are uninsured, Medicaid beneficiaries (4), cohabiting, or unmarried (1-3) - also experience disproportionately heightened rates of induced abortions and unintended pregnancies. Reflecting the extent of this public health problem, the US Department of Health and Human Services set a goal to achieve a $10 \%$ increase in the proportion of intended pregnancies by 2020 (5).

Male partners and their level of support can play an important role in maternal reproductive decisions. A few studies concerning postpartum and post-abortion contraception methods found that women expected their male partners to be involved in decisions and appreciated better informed and supportive partners $(6,7)$. For example, one study comprised of couples attending counseling for post-abortion contraception, reported $77 \%$ of women and
$59 \%$ of their respective partners expected partner involvement in the health visit (6). Moreover, partner support or opposition to contraceptive methods affected initiation and continuation of contraception $(6,7)$.

While limited by small samples and lack of control groups, results from the aforementioned studies help elucidate inconsistencies in the literature regarding effectiveness of contraceptive counseling following abortion (8-10). For example, some research show support for counseling interventions intended to improve knowledge and use of effective contraception $(8,9)$ whereas a meta-analysis by Ferreira et al (10) showed no significant differences in contraceptive use and acceptance due to contraceptive counseling among women undergoing induced abortion (odds ratio $[\mathrm{OR}]=1.32,95 \% \mathrm{CI}=0.90-1.94$ ). The variable impact of educational interventions may be partially due to differing levels of partner involvement in family planning decisions. Thus, it is important to consider the interpersonal decision-making process and behaviors in couples to prevent induced abortions due to unintended pregnancy $(11,12)$. In particular, extant literature indicates the role of abusive relationships in shaping women's 
reproductive decisions $(13,14)$.

Intimate partner violence (IPV) is a complicating factor in women's decisions to have an induced abortion. Earlier research demonstrated an association between IPV and reproductive control as indicated by decreased contraceptive use (13) and increased induced abortion (14). While much of the literature has focused on the interplay between IPV, maternal pregnancy intention $(14,15)$ and adverse birth outcomes (16), few studies have explored how the partner's desires for the pregnancy influence the reproductive decision-making process. To our knowledge, no published studies have evaluated maternal pregnancy intention in tandem with paternal pregnancy intention and the impact on induced abortions.

The current study seeks to examine the relationship between couple pregnancy intentions and induced abortion in US women.

\section{Materials and Methods}

Data came from the 2006-2010 National Survey of Family Growth (NSFG). The survey uses a multi-stage, probability sampling framework to collect information on families, relationships, fertility, and health behaviors from a nationally representative sample of US residents between 15 to 44 years of age (17). Primiparous women with at least one completed pregnancy prior to the interview date were included in the analysis. Inclusion criteria also included cohabitation with one husband or partner at the time of the first pregnancy conception to capture data on paternal characteristics. Accordingly, women who did not report cohabiting with anyone at the time of their first pregnancy, lived with multiple partners or husbands, or did not provide information about pregnancy intentions and induced abortion of first pregnancy were excluded - leaving a final sample of 4263 women.

Information on pregnancy outcomes was ascertained by the following survey question, "Now I'd like to ask some questions specifically about your pregnancy...In which of the ways shown on Card 13 did the pregnancy end?" Choices included miscarriage, stillbirth, induced abortion, ectopic or tubal pregnancy, live birth by Cesarean section, and live birth by vaginal delivery. Women whose first pregnancy ended in an induced abortion were categorized as having experienced induced abortion. Those who reported any other pregnancy outcomes were categorized as not having experienced an induced abortion.

The couple's pregnancy intentions were determined by a series of questions about each pregnancy and the wantedness of the pregnancy prior to conception. Maternal pregnancy intention was considered "intended" if women desired a child at the time of the first pregnancy, wanted it sooner, or were indifferent. A pregnancy that was mistimed or unwanted was considered "unintended" (1). Female respondents were asked similar questions to assess their partner's pregnancy desires at conception and were classified in a similar fashion. Couple pregnancy intentions were then recoded into the following: both intended $(\mathrm{M}+\mathrm{P}+)$, both unintended (M-P-), maternal intended only (M+P-), and paternal intended only (M-P+) $(18,19)$. Potential covariates were considered in accordance with the literature $(1,2,4,20)$. Individual characteristics included race/ethnicity, maternal age at interview, highest completed education, and income to poverty level. Childhood psychosocial and demographic factors included having an intact family through 18 years of age, raised religion, age of mother-figure at first child birth, and nativity. Sexual development and behavior variables consisted of age of menarche, age of first sexual encounter, and effectiveness of contraceptive method (21) used at first sexual encounter. Factors specific to first pregnancy included maternal age at conception, marital status when pregnancy began, and contraceptive use before first pregnancy. The number of years of cohabitation with partners at the time of pregnancy was also assessed.

\section{Statistical Analysis}

Descriptive statistics provided the distribution of characteristics among participants by induced abortion and couple pregnancy intention. Rao-Scott chi-square tests allowed for bivariate group comparisons for categorical variables. Logistic regression models generated OR and $95 \% \mathrm{CI}$ to examine the association between couple pregnancy intention and induced abortion. Potential confounders were included in parsimonious logistic regression models if their inclusion resulted in a $10 \%$ change or more in the OR estimate. Effect modification due to race/ethnicity was assessed using an interaction term $(P=$ 0.9149 ) but was not statistically significant; therefore race/ ethnicity was assessed as a potential confounder. Analyses accounted for the multi-stage, complex sampling design using SAS software version 9.4 (Cary, Indiana).

\section{Results}

Overall, $28.5 \%$ of women were aged 19 or younger at conception, $43.6 \%$ were not married when pregnancy began, and more than half (52.3\%) reported no pre-pregnancy contraceptive use (Table 1). Approximately $9.2 \%$ of women terminated their first pregnancy in an induced abortion (not shown in tables). Couples' intentions for pregnancy were concordant in $82.9 \%$ of cases, with $50.5 \%$ of respondents reporting mutually intended pregnancies and nearly a third $(32.3 \%)$ reporting mutually unintended pregnancies (Table 1). Among the cases of discordant pregnancy intentions $(17.1 \%)$, there was a greater prevalence of pregnancies intended by the husband/partner but not the mother $(\mathrm{M}-\mathrm{P}+; 10.1 \%)$ than pregnancies intended by the mother and not the male partner (M+P-; 7.1\%).

More women with induced abortion were non-Hispanic black, did not have an intact family in childhood, and were raised without any specified religion than those with no induced abortion $(P<0.05)$ (Table 1). Induced abortion was associated with sexual development and behavioral factors such as effectiveness of contraception at first sexual encounter and first pregnancy factors (i.e. maternal age at conception, marital status, and years of cohabitation). Pregnancies that were mutually unintended accounted for 
Table 1. Weighted Distribution of Characteristics by Induced Abortion Status

\begin{tabular}{|c|c|c|c|c|}
\hline & $\begin{array}{c}\text { Total } \\
\mathrm{n}=\mathbf{4 2 6 3}\end{array}$ & $\begin{array}{l}\text { Induced Abortion } \\
n=462\end{array}$ & $\begin{array}{l}\text { No Induced Abortion } \\
n=3801\end{array}$ & $P$ Value \\
\hline & & Weighted Colum & & \\
\hline \multicolumn{5}{|l|}{ Race/ethnicity } \\
\hline Non-Hispanic white & 59.1 & 57.2 & 59.2 & 0.0273 \\
\hline Non-Hispanic black & 14.3 & 19.4 & 13.8 & \\
\hline Hispanic & 17.7 & 12.9 & 18.2 & \\
\hline Non-Hispanic other race & 8.8 & 9.9 & 8.7 & \\
\hline \multicolumn{5}{|l|}{ Age at interview } \\
\hline $15-19$ years & 3.2 & 5.2 & 3.0 & $<0.0001$ \\
\hline $20-24$ years & 10.1 & 18.2 & 9.3 & \\
\hline $25-29$ years & 16.4 & 15.2 & 16.5 & \\
\hline $30-34$ years & 20.3 & 16.6 & 20.7 & \\
\hline $35-39$ years & 25.6 & 21.4 & 26.0 & \\
\hline $40-44$ years & 24.4 & 23.4 & 24.5 & \\
\hline \multicolumn{5}{|l|}{ Education } \\
\hline Less than high school & 18.1 & 13.7 & 18.6 & 0.0003 \\
\hline High school & 25.1 & 24.8 & 25.2 & \\
\hline Greater than high school & 56.7 & 61.6 & 56.2 & \\
\hline \multicolumn{5}{|l|}{ Income to poverty level } \\
\hline$<150 \%$ & 33.5 & 27.0 & 34.1 & 0.2274 \\
\hline $150-299 \%$ & 29.3 & 33.7 & 28.9 & \\
\hline$\geq 300 \%$ & 37.2 & 39.4 & 37.0 & \\
\hline \multicolumn{5}{|l|}{ Intact family until age 18} \\
\hline Yes & 62.3 & 47.1 & 63.8 & 0.0002 \\
\hline No & 37.7 & 52.9 & 36.2 & \\
\hline \multicolumn{5}{|l|}{ Raised religion } \\
\hline Catholicism & 34.7 & 36.5 & 34.6 & 0.0018 \\
\hline Protestantism & 46.9 & 38.8 & 47.7 & \\
\hline Other & 9.2 & 9.5 & 9.2 & \\
\hline None & 9.2 & 15.2 & 8.6 & \\
\hline \multicolumn{5}{|l|}{ Age of mother-figure at first birth } \\
\hline$<18$ years & 18.6 & 16.8 & 18.8 & 0.3408 \\
\hline$\geq 18$ years & 81.4 & 83.2 & 81.2 & \\
\hline \multicolumn{5}{|l|}{ Born outside the U.S. } \\
\hline Yes & 17.9 & 11.8 & 18.6 & 0.0295 \\
\hline No & 82.1 & 88.2 & 81.4 & \\
\hline \multicolumn{5}{|l|}{ Age of menarche } \\
\hline$<12$ years & 21.9 & 26.2 & 21.4 & 0.0114 \\
\hline 12 years & 27.4 & 30.4 & 27.1 & \\
\hline 13 years & 25.1 & 27.0 & 24.9 & \\
\hline 14 years & 14.0 & 10.7 & 14.3 & \\
\hline$\geq 15$ years & 11.7 & 5.7 & 12.3 & \\
\hline \multicolumn{5}{|l|}{ Age at first sexual encounter } \\
\hline$<15$ years & 14.8 & 31.0 & 13.1 & $<0.0001$ \\
\hline $15-17$ years & 43.1 & 47.2 & 42.7 & \\
\hline$\geq 18$ years & 42.1 & 21.7 & 44.2 & \\
\hline \multicolumn{5}{|c|}{ Effectiveness of contraception at first sexual encounter } \\
\hline Most effective & 22.5 & 11.9 & 23.5 & $<0.0001$ \\
\hline Somewhat effective & 44.5 & 51.5 & 43.8 & \\
\hline Least effective & 0.6 & 0.1 & 0.7 & \\
\hline Not effective & 32.4 & 36.5 & 31.9 & \\
\hline Maternal age at conception & & & & \\
\hline$\leq 19$ years & 28.5 & 55.9 & 25.7 & $<0.0001$ \\
\hline $20-29$ years & 55.8 & 42.1 & 57.2 & \\
\hline $30-43$ years & 15.6 & 2.0 & 17.0 & \\
\hline Marital status when pregnancy $b$ & & & & \\
\hline Married & 56.4 & 6.5 & 61.4 & $<0.0001$ \\
\hline Not married & 43.6 & 93.5 & 38.6 & \\
\hline Pre-pregnancy contraceptive use & & & & \\
\hline Yes & 47.7 & 46.3 & 47.8 & 0.7849 \\
\hline No & 52.3 & 53.7 & 52.2 & \\
\hline Years of cohabitation & & & & \\
\hline$\leq 6$ years & 28.9 & 56.6 & 27.8 & $<0.0001$ \\
\hline $7-10$ years & 22.0 & 9.1 & 22.5 & \\
\hline $11-15$ years & 24.2 & 9.7 & 24.8 & \\
\hline$\geq 16$ years & 25.0 & 24.7 & 25.0 & \\
\hline Couple pregnancy intention & & & & \\
\hline${ }^{\mathrm{a}} \mathrm{M}+\mathrm{P}+$ & 50.5 & 2.5 & 55.4 & $<0.0001$ \\
\hline${ }^{b} \mathrm{M}-\mathrm{P}-$ & 32.2 & 83.8 & 27.0 & \\
\hline${ }^{\mathrm{c}} \mathrm{M}+\mathrm{P}-$ & 7.1 & 3.1 & 7.5 & \\
\hline${ }^{d} \mathrm{M}-\mathrm{P}+$ & 10.1 & 10.5 & 10.1 & \\
\hline
\end{tabular}

Sample size is unweighted; $P$ values based on Rao-Scott $\chi^{2}$.

${ }^{a} \mathrm{M}+\mathrm{P}+\left(\right.$ both pregnancy intended); ${ }^{\mathrm{b}} \mathrm{M}-\mathrm{P}$ - (both pregnancy unintended); ${ }^{\mathrm{C}} \mathrm{M}+\mathrm{P}-$ (maternal pregnancy intended, paternal pregnancy unintended); ${ }^{d} \mathrm{M}-\mathrm{P}+$ (maternal pregnancy unintended, paternal pregnancy intended). 
a larger proportion of pregnancies ending with induced abortions (83.8\%) than of other pregnancies (27.0\%). Couples with discordant intentions accounted for a fewer proportion of induced abortions than other pregnancies (13.6\% vs. $17.6 \%$, respectively).

Table 2 shows the weighted distribution of characteristics by pregnancy intention dyads. Couples with mutually intended pregnancy $(\mathrm{M}+\mathrm{P}+)$ were more likely than other dyads to include women who were non-Hispanic white, highly educated, and married $(P<0.0001)$. Conversely, couples with mutually unintended pregnancies (M-P-) and discordant desires $(\mathrm{M}+\mathrm{P}-, \mathrm{M}-\mathrm{P}+)$ were more likely than mutually intended pregnancies to include women who were unmarried, racial/ethnic minorities, lacking a high school education, of low income, aged 19 or younger at conception, and not using contraception before pregnancy.

Compared to mutually intended pregnancies $(\mathrm{M}+\mathrm{P}+)$, mutually unintended pregnancies (M-P-) and those with discordant intentions had increased odds of having an induced abortion adjusting for income, raised religion, age of mother at first birth, maternal age at conception, marital status, and years of cohabitation (Table 3 ). The adjusted OR for induced abortion was $5.3(95 \% \mathrm{CI}=3.1-9.2)$ in discordant pregnancies in which the male partner did not intend the pregnancy and 6.9 (95\% CI=1.5-32.9) when the female partner did not intend the pregnancy. Consistent results were obtained in analyses where maternal and paternal pregnancy intentions were assessed separately (Table 4). Women with unintended pregnancy had significantly increased odds of having an induced abortion after accounting for confounding factors $(A O R=12.8,95 \%$ $\mathrm{CI}=2.2-73.6$ ). Women whose partners did not intend the pregnancy were more than eight times as likely to have an induced abortion $(\mathrm{AOR}=8.6,95 \% \mathrm{CI}=5.1-14.7)$.

\section{Discussion}

This study found a significant association between couples' pregnancy intentions and the rate of induced abortions, a relationship few prior studies have explored $(18,19)$. Using NSFG data, Williams (18) found that $61.9 \%$ of women reported their first pregnancy was desired by both partners, $5.6 \%$ as wanted by only the woman, $6.9 \%$ as wanted by only the male partner, and $23.1 \%$ as wanted by neither. That analysis did not include pregnancies that ended in induced abortions and those that occurred despite the use of contraception (i.e. contraceptive failures). This exclusion may explain the higher prevalence of discordant and concordant unintended pregnancy intentions observed in our study. Our findings showed discordant couple intentions had up to a seven-fold increased odds of induced abortion than couples in which both intended the pregnancy. Furthermore, couples with mutual unintended pregnancy were significantly more likely to have an elective termination than couples in which both intended the pregnancy. Significant differences between the concordant pregnancy intention groups suggest that couples with mutually unintended pregnancy have challenges with access to and utili- zation of contraception. This is not surprising given more than half of all mutually unintended pregnancies were comprised of women aged 19 or younger at conception. Although a recent study showed teen unintended pregnancy rates declined in 2001 to 2006, unintended pregnancies ending in abortion also increased in this high-risk group (1) which suggests a need for improved access to effective contraceptives. Data from the national Pregnancy Risk Assessment Monitoring System (2004-2008) indicated $13.1 \%$ of young mothers who did not use contraception reported difficulties accessing birth control as a reason for nonuse (22). Other reasons included misconceptions, experiencing side-effects, and partners not wanting to use contraception (22). Moreover, intentions to avoid pregnancy do not necessarily give rise to safe sexual practice in couples. In one qualitative study, young mothers who stated that their pregnancies were unintended also reported impulsive and unprotected sexual activity due to feeling pressured to have sex, contraceptive coercion, and lack of thought to the consequences (23).

A woman's ability to make reproductive decisions can be compromised in abusive relationships $(13,24,25)$. Abused women are at increased risk of experiencing repeat induced abortion, miscarriage, and problems with contraceptive use (13). While extant research has focused on themes related to partners' negative influence on contraceptive use, cases where male partners pressured or coerced women into terminating pregnancies have been less understood (25). A common practice in epidemiologic research is to assume that all elective terminations result from unintended pregnancies when in fact, it has been estimated that $5 \%-8 \%$ of induced abortions occur among women who intended the pregnancies $(1,2)$. This prevents researchers from fully exploring couple dynamics and attitudes towards pregnancy; especially in cases where males, in contrast to their female partners, do not desire children. Although some cases of abortion following an intended pregnancy may be due to changes in maternal wishes (26), previous research highlights the possible role of the partner in general, and IPV in particular, in shaping reproductive decisions $(14,27)$.

This study found that the odds of abortion were increased when women did not intend pregnancy but the male partner did. However, reasons for seeking termination of pregnancy are far more complex and multifaceted than women simply not intending to become pregnant (28). Finer et al (29) evaluated common reasons for having an abortion among patients seeking pregnancy termination such as interference with school/career, ability to care for existing dependents, resource or financial difficulties, and no desire for single motherhood. Of interest were factors related to partners such as lack of support, partner wanting an abortion, and abusive relationships. Women who have no desire for pregnancy may not inform partners of their decision to have an induced abortion for these and other reasons $(27,30)$. A recent meta-analysis reported that compared to women in non-violent relationships, abused women were twice as likely to have concealed the preg- 
Table 2. Weighted Distribution of Characteristics by Couple Pregnancy Intention Dyads

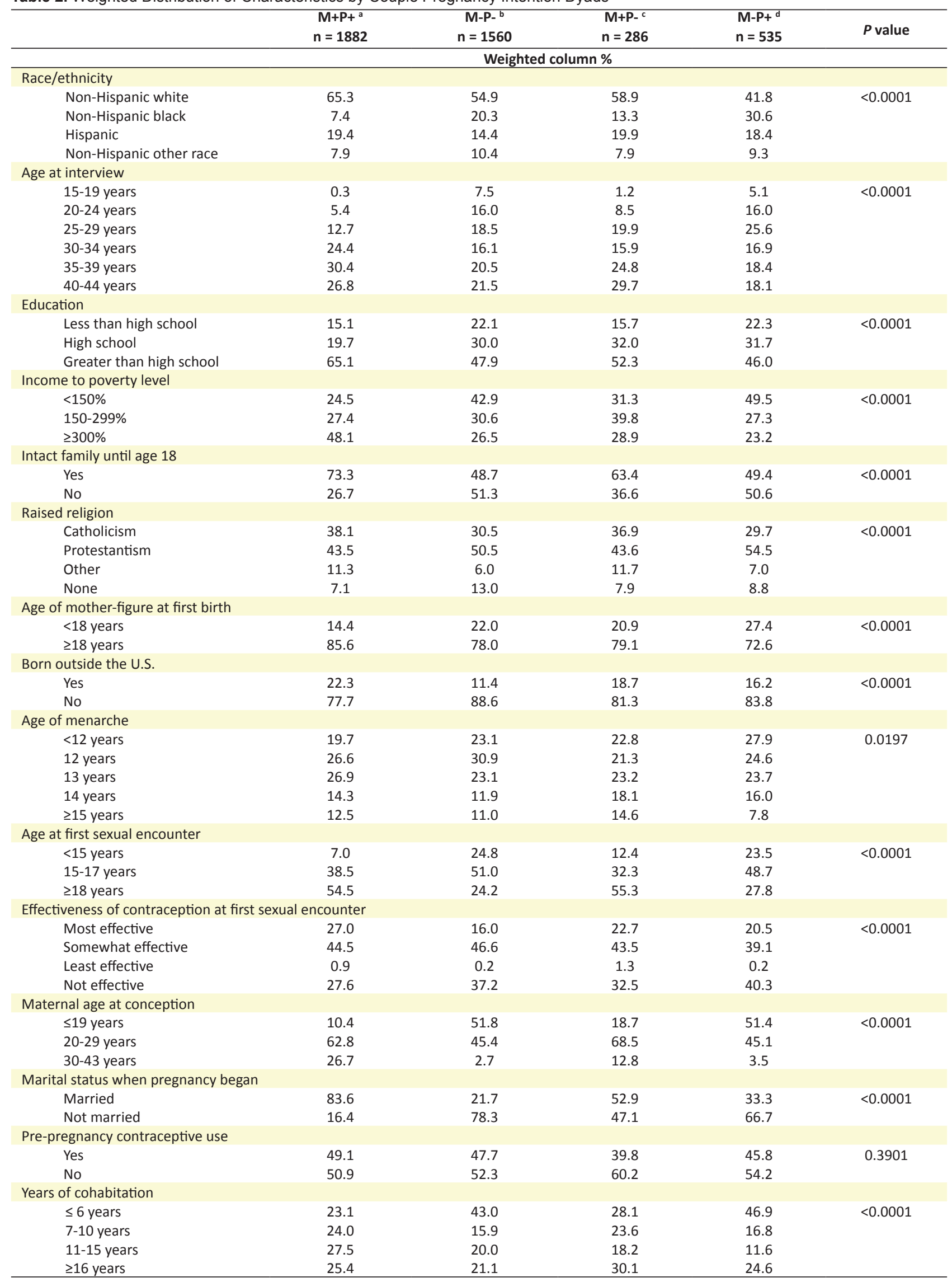

Sample size is unweighted; $p$-values based on Rao-Scott $\chi^{2}$.

${ }^{a} \mathrm{M}+\mathrm{P}+$ (both pregnancy intended); ${ }^{\mathrm{b}} \mathrm{M}-\mathrm{P}$ - (both pregnancy unintended); ${ }^{\mathrm{c}} \mathrm{M}+\mathrm{P}$ - (maternal pregnancy intended, paternal pregnancy unintended); ${ }^{\mathrm{d}}$ $M-P+$ (maternal pregnancy unintended, paternal pregnancy intended). 
Table 3. Logistic Regression Analysis for Predicting Induced Abortion Among Couple Pregnancy Intention Dyads

\begin{tabular}{|c|c|c|}
\hline $\begin{array}{l}\text { Couple Pregnancy } \\
\text { Intention Dyads }\end{array}$ & $\begin{array}{c}\text { COR } \\
(95 \% \mathrm{Cl})\end{array}$ & $\begin{array}{c}\text { AOR }{ }^{a} \\
(95 \% \mathrm{Cl})\end{array}$ \\
\hline $\mathrm{M}+\mathrm{P}+$ & 1.00 & 1.00 \\
\hline M-P- & *68.5 (31.1-151.1) & *29.5 (5.8-1 \\
\hline$M+P-$ & *9.2 (5.3-15.8) & *5.3 (3.1 \\
\hline $\mathrm{M}-\mathrm{P}+$ & *23.0 (11.7-45.5) & *6.9 (1.5- \\
\hline \multicolumn{3}{|c|}{$\begin{array}{l}\text { COR, crude odds ratio; } \mathrm{AOR} \text {, adjusted odds ratio; } \mathrm{M}+\mathrm{P}+\text { (both pregnancy } \\
\text { intended), M-P- (both pregnancy unintended), M+P- (maternal } \\
\text { pregnancy intended, paternal pregnancy unintended), M-P+ (maternal } \\
\text { pregnancy unintended, paternal pregnancy intended). } \\
\text { a Estimates controlling for income, raised religion, age of mother- } \\
\text { figure at first birth, maternal age at conception, marital status, years } \\
\text { of cohabitation. } \\
\text { *Statistically significant. }\end{array}$} \\
\hline
\end{tabular}

Table 4. Logistic Regression Analysis for Predicting Induced Abortion by Maternal or Paternal Pregnancy Intention

\begin{tabular}{lll}
\hline Pregnancy Intention & COR $(95 \% \mathrm{Cl})$ & AOR $(95 \% \mathrm{Cl})$ \\
\hline $\begin{array}{l}\text { Maternal } \\
\text { Intended }\end{array}$ & 1.00 & 1.00 \\
$\quad$ Unintended & $* 29.5(13.4-65.0)$ & ${ }^{\mathrm{a}, *} 12.8(2.2-73.6)$ \\
Paternal & & 1.00 \\
$\quad$ Intended & 1.00 & $\mathrm{~b}, * 8.6(5.1-14.7)$ \\
$\quad$ Unintended & $* 12.7(8.3-19.2)$ & $\mathrm{b}$
\end{tabular}

COR, crude odds ratio; AOR, adjusted odds ratio.

${ }^{a}$ Estimate controlling for marital status, years of cohabitation, maternal race/ethnicity, nativity, raised religion.

${ }^{b}$ Estimate controlling for marital status, years of cohabitation.

*Statistically significant.

nancy termination from partners (27). These underscore the importance of comprehensive violence prevention and family planning services to decrease the risk of unintended pregnancy.

Study strengths include using a nationally representative dataset to allow greater generalizability of results. The NSFG data utilizes standardized data collection methods and multiple modalities to minimize information bias and improve response rates, especially for sensitive questions. Other strengths include accounting for childhood and paternal characteristics that may affect decisions about pregnancy. Limitations of the study include the inability to determine causation due to the cross-sectional design and recall bias stemming from the reliance on the mother to characterize the intentions of the husband or partner. While research in this area is scant, studies have found good agreement between women's perceptions of partner pregnancy intentions and self-report by partners (11) and accurate reports of husbands' attitudes about fertility (31). Furthermore, irrespective of accuracy, perceptions of paternal pregnancy intention may influence women's health behavior and warrants examination. Underreporting of induced abortions may occur; however, a previous study using the 2002 NSFG data did not find that the duration of time since an abortion affected respondents' recall (32). Uncontrolled confounding due to IPV may have affected the results but was unavailable in the NSFG dataset. Nevertheless, cases where pregnancies were intended by women but unintended by partners may reflect a risk for pregnancy coercion and other forms of IPV $(25,33)$.

\section{Conclusion}

A woman's decision to have an induced abortion is influenced by her relationships and the social context within which the pregnancy takes place $(6,7)$. Health providers may need to take into account the circumstances and factors affecting decision-making and health behaviors in couples to reduce unintended pregnancies. While the male partner is not necessary for effective pregnancy care, their role in shaping management decisions should not be overlooked. Women in healthy relationships can benefit from having frequent conversations about pregnancy with their partners. Furthermore, integrated family planning and violence prevention services may be essential to improving the continuum of care and reproductive health outcomes for women.

\section{Ethical Issues}

The research was approved as exempt by the Institutional Review Board at Virginia Commonwealth University. This study used a de-identified, publicly-available dataset from the National Center for Health Statistics.

\section{Conflict of Interests}

None to be declared.

\section{Financial Support}

This research was supported by Department of Health and Human Services, Agency for Healthcare Research and Quality grants R36HS023724 and 1R01HS021504-01A1. The content is solely the responsibility of the authors and does not necessarily represent the official views of the Agency for Healthcare Research and Quality.

\section{Disclosure}

Findings were presented at the Women's Health 24th Annual Congress, April 14-17, 2016 in Washington, DC.

\section{References}

1. Finer LB, Zolna MR. Unintended pregnancy in the United States: Incidence and disparities, 2006. Contraception. 2011;84(5):478-485. doi:10.1016/j. contraception.2011.07.013.

2. Finer LB, Henshaw SK. Disparities in rates of unintended pregnancy in the United States, 1994 and 2001. Perspect Sex Reprod Health. 2006;38(2):90-96. doi:10.1363/3809006.

3. Jones RK, Kavanaugh ML. Changes in abortion rates between 2000 and 2008 and lifetime incidence of abortion. Obstet Gynecol. 2011;117(6):1358-1366. doi:10.1097/ AOG.0b013e31821c405e.

4. Jones RK, Darroch JE, Henshaw SK. Patterns in the socioeconomic characteristics of women obtaining abortions in 2000-2001. Perspect Sex Reprod Health 2002;34(5):226-235. doi:10.2307/3097821.

5. U.S. Department of Health and Human Services, Office of Disease Prevention and Health Promotion. Family planning. Healthy People 2020 Web site. http:// www.healthypeople.gov/2020/topicsobjectives2020/ objectiveslist.aspx?topicId=13. Updated 2013. Accessed February 18, 2016.

6. Becker S, Bazant ES, Meyers C. Couples counseling at an abortion clinic: A pilot study. Contraception. 2008;78(5):424-431. doi:10.1016/j. 
contraception.2008.06.011.

7. Lewis DA, Martins SL, Gilliam ML. Partner roles in contraceptive use: what do adolescent mothers say? J Pediatr Adolesc Gynecol. 2012;25(6):396-400. doi:10.1016/j.jpag.2012.08.003.

8. Zapata LB, Tregear SJ, Curtis KM, et al. Impact of contraceptive counseling in clinical settings: A systematic review. Am J Prev Med. 2015;49(2S1): S31-S45. doi:10.1016/j.amepre.2015.03.023.

9. Nobili MP, Piergrossi S, Brusati V, Moja EA. The effect of patient-centered contraceptive counseling in women who undergo a voluntary termination of pregnancy. Patient Educ Couns. 2007;65(3):361-368. doi:10.1016/j. pec.2006.09.004.

10. Ferreira ALCG, Lemos A, Figueiroa JN, de Souza AI. Effectiveness of contraceptive counselling of women following an abortion: A systematic review and metaanalysis. Eur J Contracept Reprod Health Care. 2009; 14(1):1-9. doi:10.1080/13625180802549970.

11. Kraft JM, Harvey SM, Hatfield-Timajchy $\mathrm{K}$, et al. Pregnancy motivations and contraceptive use: Hers, his, or theirs? Womens Health Issues. 2010;20(4): 234-241. doi:10.1016/j.whi.2010.03.008.

12. Kavanaugh ML, Lindberg LD, Frost J. Factors influencing partners' involvement in women's contraceptive services. Contraception 2012;85(1): 83-90. doi:10.1016/j. contraception.2011.04.018.

13. Cha S, Chapman DA, Wan W, Burton CW, Masho SW. Intimate partner violence and postpartum contraceptive use: the role of race/ethnicity and prenatal birth control counseling. Contraception 2015; 92: 268-275. doi:10.1016/j.contraception.2015.04.009.

14. Pallitto CC, García-Moreno C, Jansen HA, Heise L, Ellsberg M, Watts C. Intimate partner violence, abortion, and unintended pregnancy: Results from the WHO multicountry study on women's health and domestic violence. Int J Gynaecol Obstet. 2013; 120(1):3-9. doi:10.1016/j. ijgo.2012.07.003.

15. Chu SY, Goodwin MM, D’Angelo DV. Physical violence against U.S. women around the time of pregnancy, 20042007. Am J Prev Med. 2010;38(3):317-322. doi:10.1016/j. amepre.2009.11.013.

16. Sharps PW, Laughon K, Giangrande SK. Intimate partner violence and the childbearing year: Maternal and infant health consequences. Trauma Violence Abuse. 2007;8(2):105-116. doi:10.1177/1524838007302594.

17. Groves RM, Mosher WD, Lepkowski JM, Kirgis NG. Planning and development of the continuous National Survey of Family Growth. Vital Health Stat 1 2009; 48: 1-64.

18. Williams LB. Determinants of couple agreement in U.S. fertility decisions. Fam Plann Perspect. 1994; 26(4):169173. doi: $10.2307 / 2136242$.

19. Hohmann-Marriott B. The couple context of pregnancy and its effects on prenatal care and birth outcomes. Matern Child Health J. 2009;13(6):745-754. doi:10.1007/ s10995-009-0467-0.

20. Coker AL. Does physical intimate partner violence affect sexual health? A systematic review. Trauma Violence Abuse 2007;8(2):149-177. doi:10.1177/1524838007301162.

21. Trussell J. The cost of unintended pregnancy in the United States. Contraception. 2007;75(3):168-170. doi:10.1016/j. contraception.2006.11.009.

22. Centers for Disease Control and Prevention. Prepregnancy contraceptive use among teens with unintended pregnancies resulting in live births - Pregnancy Risk Assessment Monitoring System (PRAMS), 2004-2008. MMWR. 2012;61(2):25-29.

23. Herrman JW. Repeat pregnancy in adolescence: Intentions and decision making. MCN Am J Matern Child Nurs. 2007;32(2):89-94.

24. Miller E, Jordan B, Levenson R, Silverman JG. Reproductive coercion: connecting the dots between partner violence and unintended pregnancy. Contraception. 2010;81(6):457459. doi:10.1016/j.contraception.2010.02.023.

25. MooreAM,FrohwirthL, MillerE.Malereproductivecontrol of women who have experienced intimate partner violence in the United States. Soc Sci Med. 2010;70(11):1737-1744. doi:10.1016/j.socscimed.2010.02.009.

26. Poole V, Flowers J, Goldenberg R, Cliver S, McNeal S. Changes in intendedness during pregnancy in a highrisk multiparous population. Matern Child Health J 2000;4(3):179-182. doi:10.1023/A:1009523430135.

27. Hall M, Chappell LC, Parnell BL, Seed PT, Bewley S. Associations between intimate partner violence and termination of pregnancy: A systematic review and metaanalysis. PLoS Med. 2014;11(1):e1001581. doi:10.1371/ journal.pmed.1001581.

28. Bankole A, Singh S, Haas T. Reasons why women have induced abortions: evidence from 27 countries. Int Fam Plan Perspect. 1998; 24(3):117-152. doi:10.2307/3038208.

29. Finer LB, Frohwirth LF, Dauphinee LA, Singh S, Moore AM. Reasons U.S. women have abortions: Quantitative and qualitative perspectives. Perspect Sex Reprod Health. 2005;37(3):110-118. doi:10.1111/j.1931-2393.2005. tb00045.x.

30. Woo J, Fine P, Goetzl L. Abortion disclosure and the association with domestic violence. Obstet Gynecol. 2005;105(6):1329-1334. doi:10.1097/01. AOG.0000159576.88624.d2.

31. Goldscheider FK, Kaufman G. Fertility and commitment: bringing men back in. Popul Dev Rev. 1996; 22: 87-99. doi: $10.2307 / 2808006$.

32. Jones RK, Kost K. Underreporting of induced and spontaneous abortion in the United States: an analysis of the 2002 National Survey of Family Growth. Stud Fam Plann. 2007;38(3):187-197. doi:10.1111/j.17284465.2007.00130.x.

33. Miller E, Decker MR, McCauley HL, et al. Pregnancy coercion, intimate partner violence and unintended pregnancy. Contraception. 2010;81(4):316-322. doi:10.1016/j.contraception.2009.12.004.

Copyright ( 2016 The Author(s); This is an open-access article distributed under the terms of the Creative Commons Attribution License (http://creativecommons.org/licenses/by/4.0), which permits unrestricted use, distribution, and reproduction in any medium, provided the original work is properly cited. 